\title{
Compound Temperature and Precipitation Events in the Czech Republic: Differences of Stratiform versus Convective Precipitation in Station and Reanalysis Data
}

\author{
Zuzana Rulfová, Romana Beranová *(D) and Eva Plavcová
}

Citation: Rulfová, Z.; Beranová, R.; Plavcová, E. Compound Temperature and Precipitation Events in the Czech Republic: Differences of Stratiform versus Convective Precipitation in Station and Reanalysis Data.

Atmosphere 2021, 12, 87.

https://doi.org/10.3390/atmos12010087

Received: 2 December 2020

Accepted: 5 January 2021

Published: 8 January 2021

Publisher's Note: MDPI stays neutral with regard to jurisdictional clai$\mathrm{ms}$ in published maps and institutional affiliations.

Copyright: (C) 2021 by the authors. Licensee MDPI, Basel, Switzerland. This article is an open access article distributed under the terms and conditions of the Creative Commons Attribution (CC BY) license (https:// creativecommons.org/licenses/by/ $4.0 /)$.
Institute of Atmospheric Physics CAS, 14131 Prague, Czech Republic; rulfova@ufa.cas.cz (Z.R.); plavcova@ufa.cas.cz (E.P.)

* Correspondence: rber@ufa.cas.cz

\begin{abstract}
Some natural hazards may result from the coincidences of anomalies of different climatic variables. These so-called compound events can cause extreme impacts. This study analyzes compounds of extreme temperature with notable convective and stratiform precipitation in the Czech Republic during 1982-2016. Characteristics of compound events obtained from 11 stations' data are compared with those from the gridded ERA-Interim reanalysis. We found that notable stratiform precipitation frequently coincides with warm nights and warm days in winter but with cold days in the other seasons. While the winter stratiform precipitation coinciding with warm days and warm nights is linked to anticyclonic, southwest, northwest, and anticyclonic-northwest circulation types, the northeast type is the most crucial circulation type linked to notable stratiform precipitation coinciding with cold days in all seasons except winter. The compound events of notable convective precipitation occur most frequently in summer and they are joined mainly with warm days. These compound events are associated with anticyclonic, cyclonic, and northwest circulation types. Although the number of days with stratiform compound events is larger in ERA-Interim than in the station data, the results are qualitatively comparable. ERA-Interim is, however, not able to reproduce convective compound events obtained from the station data.
\end{abstract}

Keywords: compound events; temperature; stratiform precipitation; convective precipitation; atmospheric circulation; Czech Republic

\section{Introduction}

Compound events are multivariate extreme events wherein the contributing variables may not be an extreme in and of themselves but their joint occurrences can intensify their impacts [1,2]. Examples of high-impact compound events include summer hot and dry events [3], the combination of storm surge and floods [1], and the concomitant occurrence of extreme precipitation and winds [4]. In the recent years, the analysis of compound events has been receiving increasing attention $[5,6]$.

A widely examined compound event is the coincident occurrence of intense precipitation and extreme temperature $[3,7,8]$. In winter, the joint occurrence of low temperature and intense precipitation may cause substantial difficulties in transportation (e.g., snow on roads [9]). On the other hand, the coincidence of high temperature and intense precipitation in winter and spring may accelerate snow melting and may cause floods [10]. During the growing season, some compound events have strong impacts on agriculture. The coincidence of cold weather with intense precipitation may trigger the development of plant diseases (e.g., mildew [11]), while intense precipitation during extremely warm days may indicate intense convective storms accompanied by risks of damaging phenomena such as hails and high winds.

In Europe, the four joint quantile events of temperature and precipitation (i.e., drywarm, dry-cold, wet-warm, and wet-cold) were analyzed by Beniston [12], who found that 
the temporal evolution of these compound events reveals a systematic change throughout the course of the 20th century, with a significant decline in the frequency of cold modes and a rise in that of warm modes. This was confirmed by Arsenović et al. [13] for Serbia. Although there are some studies focusing on compound precipitation and temperature extremes, e.g., $[7,14]$, there is no study distinguishing temperature extremes occurring with convective precipitation from those with stratiform precipitation. In central Europe, the two components of precipitation are comparable in their contribution to the overall summer rainfall amounts, but they differ considerably in manifesting temporal and spatial variability that is fundamentally related to the hydrological response (heavy convective precipitation may cause flash floods while large-scale floods are connected mainly with intense stratiform precipitation).

Convective and stratiform precipitation are associated with different ice particle growth mechanisms in clouds, and both play important roles in determining the precipitation amounts falling during the warm half-year in mid-latitudes. Since (i) convective precipitation increases with temperature faster than does stratiform precipitation (as shown, for example, in [15] for observed data in Germany) and (ii) the proportion of seasonal convective precipitation amount relative to the total precipitation amount tends to be higher in future climate projections in all seasons when convective precipitation plays an important role (i.e., from spring to autumn, as shown in [16] for Switzerland and in [17] for the Czech Republic), it is important to study the compound events of convective and stratiform precipitation separately.

For comparing climatic characteristics of different datasets, one can use global (fixed) thresholds or subsample-specific (relative) thresholds. Global thresholds (e.g., $10 \mathrm{~mm} /$ day for heavy precipitation days in [18]) are useful for checking the reproduction of observed events, for the analysis of temporal evolution, or in impact studies when the adaptation effect is excluded (e.g., if a dam was constructed before the study period, the flood risk can be assessed with extreme events related to fixed thresholds). Relative thresholds are useful, e.g., for making comparisons between the climates of distant regions or in impact studies when adaptation to the change of the means is supposed. In the present analysis, we use the latter (percentiles of the distributions).

The main mechanism driving the formation of extreme events in mid-latitudes is large-scale atmospheric circulation. Previous studies have investigated the influence of circulation on extreme temperature [19-21] and precipitation [22,23]. Studies dealing with links between atmospheric circulation and European compound events are very rare [13].

In this study, we analyze occurrences of compound temperature and precipitation events, focusing on differences between stratiform and convective precipitation. We compare the results obtained from station data and the ERA-Interim reanalysis over the Czech Republic (central Europe). Finally, we examine the relationships between the compound events and the large-scale atmospheric circulation.

\section{Data and Methods}

\subsection{Observed Data and Reanalysis}

The station precipitation and temperature data analyzed in this study came from SYNOP (surface synoptic observation) reports at 11 stations operated by the Czech Hydrometeorological Institute during the period 1982-2016. The spatial distribution of the stations can be seen in Figure 1. Locations of the stations range from lowlands to mountains while no climatological region is overrepresented. Table 1 shows that the altitudes of the stations range from 241 to $1322 \mathrm{~m}$ a.s.l. and the mean is $583 \mathrm{~m}$. Basic quality control procedures have been applied to all series in order to identify errors and suspicious readings [24]. The time series of daily convective and stratiform precipitation amounts were obtained using an algorithm that subdivides 6-h precipitation amounts into convective and stratiform types based on hourly weather state data and cloud type information. The algorithm is set up on the grounds of the experience that convective and stratiform precipitation fall from different clouds and are characterized by different types of weather events (e.g., drizzle, rain shower, 
thunderstorm, etc.), coded as weather states in the SYNOP reports (the methodology is explained in more detail in [24]).

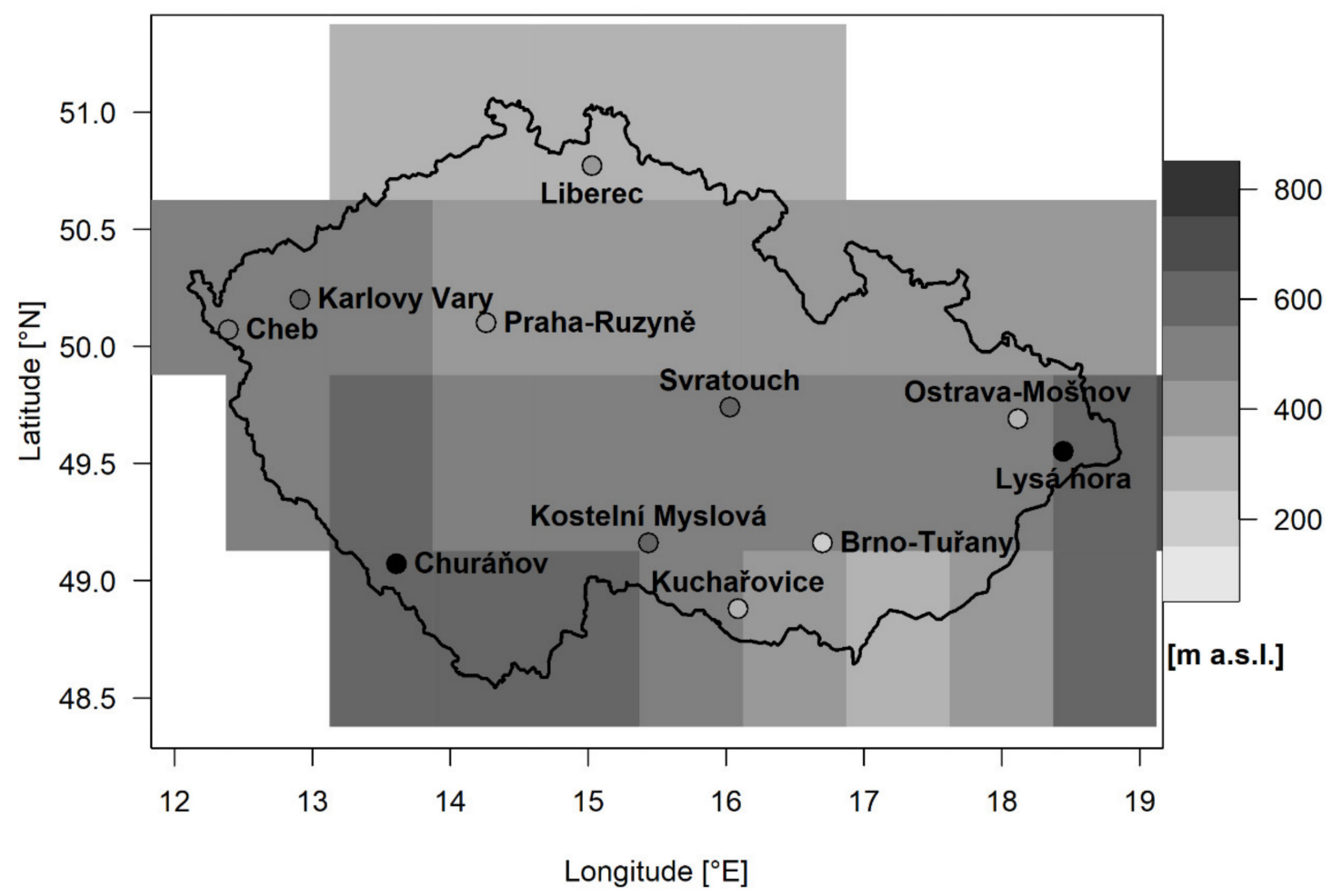

Figure 1. Orography of the ERA-Interim grid boxes and locations of stations with their altitudes (black dots are mountain stations with altitude above $1000 \mathrm{~m}$ a.s.l.).

Table 1. SYNOP stations used in the study.

\begin{tabular}{ccccc}
\hline WMO Code & Station Name & Longitude $\left[{ }^{\circ} \mathbf{E}\right]$ & Latitude $\left[{ }^{\circ} \mathbf{N}\right]$ & Altitude [m a.s.1.] \\
\hline 11723 & Brno-Tuřany & 16.70 & 49.16 & 241 \\
11782 & Ostrava-Mošnov & 18.12 & 49.69 & 251 \\
11698 & Kuchařovice & 16.09 & 48.88 & 334 \\
11518 & Praha-Ruzyně & 14.26 & 50.10 & 364 \\
11603 & Liberec & 15.03 & 50.77 & 398 \\
11406 & Cheb & 12.39 & 50.07 & 471 \\
11636 & Kostelní Myslová & 15.44 & 49.16 & 569 \\
11414 & Karlovy Vary & 12.91 & 50.20 & 603 \\
11683 & Svratouch & 16.03 & 49.74 & 737 \\
11457 & Churáňov & 13.61 & 49.07 & 1118 \\
11787 & Lysá hora & 18.45 & 49.55 & 1322 \\
\hline
\end{tabular}

We compared the station precipitation and temperature data with data from the ERAInterim reanalysis [25]. Because ERA-Interim has horizontal resolution of $0.75^{\circ}$, there are 33 grid boxes over the area of the Czech Republic. We note that the orography is smoothed in the ERA-Interim in comparison to the stations used (Figure 1): the altitude ranges from 311 to $672 \mathrm{~m}$ a.s.l. and the mean over the grid boxes is $463 \mathrm{~m}$. We have to keep in mind that smoother terrain and rather large deviations from the real altitude imply worse representation of extreme precipitation [26].

To analyze compound events, we used daily maximum (Tx) and minimum (Tn) temperature and daily precipitation data. Daily sea level pressure data (SLP) from ERA-Interim were used in order to determine circulation types over Central Europe (see Section 2.3). All analyses are conducted for four seasons: winter (DJF), spring (MAM), summer (JJA) and autumn $(\mathrm{SON})$. 


\subsection{Compound Events}

The compound events of this study are defined as simultaneous occurrences of a notable daily precipitation amount and an extreme value of $\mathrm{Tx}$ or $\mathrm{Tn}$. Notable precipitation events are defined as days with daily precipitation amounts exceeding the 75th percentile of the distribution of rainy days. The given percentile was calculated empirically from the sample of all rainy days over a 29-day running window centered on each calendar day for each station or grid. Rainy days are defined as days with precipitation amount $>0.1 \mathrm{~mm}$. Notable precipitation events were computed for total, convective, and stratiform precipitation separately. Four temperature extremes were defined based on Tx and Tn (see Table 2). The thresholds for temperature extremes were computed as the 10th and 90th percentiles of the empirical distribution of daily $\mathrm{Tx}$ and $\mathrm{Tn}$ for each calendar day through the 35-year period. Since temperature is a smoother variable than precipitation, a 5-day running window was used in this case.

Table 2. Definition of temperature extremes. Mean January, April, July, and October temperature thresholds calculated as the mean for 11 stations.

\begin{tabular}{cccccc}
\hline $\begin{array}{c}\text { Temperature } \\
\text { Extremes }\end{array}$ & Threshold & $\begin{array}{c}\text { January } \\
{\left[{ }^{\circ} \mathbf{C}\right]}\end{array}$ & $\begin{array}{c}\text { April } \\
{\left[{ }^{\circ} \mathbf{C}\right]}\end{array}$ & $\begin{array}{c}\text { July } \\
{\left[{ }^{\circ} \mathbf{C}\right]}\end{array}$ & $\begin{array}{c}\text { October } \\
{\left[{ }^{\circ} \mathbf{C}\right]}\end{array}$ \\
\hline Warm days $(\mathrm{Tx} 90)$ & $\mathrm{Tx}>$ 90th percentile & 6.4 & 18.2 & 28.4 & 17.3 \\
Warm nights $(\mathrm{Tn} 90)$ & $\mathrm{Tn}>$ 90th percentile & 1.1 & 7.4 & 16.4 & 9.5 \\
Cold days $(\mathrm{Tx} 10)$ & $\mathrm{Tx}<$ 10th percentile & -6.1 & 4.9 & 16.0 & 5.9 \\
Cold nights $(\operatorname{Tn} 10)$ & $\mathrm{Tn}<$ 10th percentile & -12.0 & -1.9 & 8.5 & -0.4 \\
\hline
\end{tabular}

For each type of the examined compound events, the percentage of days with a compound event divided by the total extreme-temperature events for a given season was calculated as follows:

$$
x=100 \frac{n_{1}}{n_{1}+n_{2}}
$$

where $\mathrm{n}_{1}$ stands for the number of days with both extremes occurring simultaneously (days with a compound event) and $\mathrm{n}_{2}$ represents the sum of days with the given kind of temperature extreme but without notable precipitation. In the absence of statistical dependency between the occurrence of notable precipitation and temperature extremes, $x$ is equal to the percentage of notable precipitation expected for that season, which can be calculated as the exceedance rate (i.e., 0.25 in the case of the 75th percentile threshold for precipitation) multiplied by the probability of a rainy day $(\mathrm{p})$ :

$$
y=0.25 * p
$$

The precipitation probability changes from season to season and for individual stations. The mean value of total precipitation probability over the year and all examined stations is $44 \%$ (range over stations is $35-54 \%$ ). Therefore, the expected probability of notable precipitation is about $11 \%(9-13 \%)$. The proportion

$$
R=\frac{x}{y}
$$

gives the ratio between the detected and expected percentages of compound events. $\mathrm{R}>1$ indicates a positive relationship (i.e., higher frequency of the compound event than expected under the assumption of independence) and $\mathrm{R}<1$ denotes a negative relationship (i.e., lower frequency than expected).

\subsection{Large-Scale Atmospheric Circulation}

To classify the daily mean states of atmospheric circulation, we used objective classification schemes based on circulation indices introduced by Jenkinson and Collison [27]. The use of objective methods for classifying circulation types represents an advantage over 
subjective methods, such as Grosswetterlagen (Hess-Brezowsky) catalogues, since the objective methods enable validation of climate model outputs and are applicable for various regions. Three circulation indices-flow direction (DIR), flow strength (STR), and flow vorticity (VORT) - were calculated from the gridded SLP over Central Europe $\left(0-30^{\circ} \mathrm{E}, 40-60^{\circ}\right.$ $\mathrm{N})$. STR represents the total resultant of the westerly (zonal) and the southerly (meridional) components of the geostrophic surface wind. VORT stands for the sum of westerly and southerly vorticities which reflects the rotation of an air mass. The equations used for the calculation of the indices are taken from [28] and given in the Supplementary Materials.

Using these indices, we define 15 circulation types: cyclonic (C), anticyclonic (A), 4 straight (directional) types (divided into four sectors: northeast (NE), southeast (SE), southwest (SW), and northwest (NW)), 8 hybrid types (combination of $\mathrm{C}$ and A types with the 4 straight types), and 1 unclassified (U) type (when both STR and the absolute value of VORT are smaller than a given threshold). Their definitions and abbreviations are given in Table 3. All circulation types were calculated from the ERA-Interim pressure data. In the investigated area of Central Europe, the most frequent circulation type is A (30\% of all days in winter and $35 \%$ in summer) together with westerly straight types in winter (SW 15\% and NW 10\%) and northerly straight types in summer (NE and NW, both $8 \%$ of days).

Table 3. Circulation type definitions and their abbreviations.

\begin{tabular}{|c|c|c|c|}
\hline \multirow[t]{2}{*}{ DIR } & \multirow{2}{*}{$\begin{array}{l}\text { Straight Types } \\
\text { | VORT I < STR }\end{array}$} & \multicolumn{2}{|c|}{$\begin{array}{c}\text { Hybrid Types } \\
\mathrm{STR} \leq \mid \text { VORT } \mid<2 \times \mathrm{STR}\end{array}$} \\
\hline & & VORT $>0$ & VORT $<0$ \\
\hline $0-90^{\circ}$ & northeast (NE) & cyclonic northeast (CNE) & anticyclonic northeast (ANE) \\
\hline $90-180^{\circ}$ & southeast (SE) & cyclonic southeast (CSE) & anticyclonic southeast (ASE) \\
\hline $180-270^{\circ}$ & southwest (SW) & cyclonic southwest (CSW) & anticyclonic southwest (ASW) \\
\hline $270-360^{\circ}$ & northwest (NW) & cyclonic northwest (CNW) & anticyclonic northwest (ANW) \\
\hline & $\begin{array}{l}\mathrm{STR}<4 \text { and } \\
|\mathrm{VORT}|<4\end{array}$ & \multicolumn{2}{|c|}{$|\mathrm{VORT}| \geq 2 \times \mathrm{STR}$} \\
\hline & unclassified (U) & cyclonic $(\mathrm{C})$ & anticyclonic (A) \\
\hline
\end{tabular}

The circulation type ratio $\left(\mathrm{R}_{\mathrm{c}}\right)$ for the compound events with the given circulation type is calculated by Equation (4):

$$
\mathrm{Rc}=\% C E / \% C T
$$

where $\% \mathrm{CE}$ is the percentage of days with both the compound event and the given circulation type and \%CT presents percentage of days with the circulation type. Both \%CE and \%CT are computed from all days in the season over the whole 35-year period. $R_{c}>1$ means that the occurrence of the circulation type during compound event days is higher than the mean climatic occurrence.

\section{Results}

\subsection{Basic Characteristics of Precipitation and Temperature}

The mean annual cycle of precipitation amounts averaged over all the 11 stations and 33 grid cells are depicted in Figure 2 (top). The maximum of monthly convective precipitation from stations (52 mm, with standard deviation (SD) $12 \mathrm{~mm}$ ) occurs in July, while the monthly mean declines almost to zero in February (4 mm, SD $3 \mathrm{~mm}$ ). Monthly stratiform precipitation amounts are nearly constant during the year and range from 33 to $48 \mathrm{~mm}$ with SD around $20 \mathrm{~mm}$. The annual cycle of total precipitation is composed of convective and stratiform precipitation, with mean July value of $96 \mathrm{~mm}$ (SD $35 \mathrm{~mm}$ ) and mean February value of $39 \mathrm{~mm}$ (SD $23 \mathrm{~mm}$ ). At most stations, the mean yearly proportion of convective precipitation within the total amount of precipitation is around $30 \%$ and this rises to about $50 \%$ in summer. 

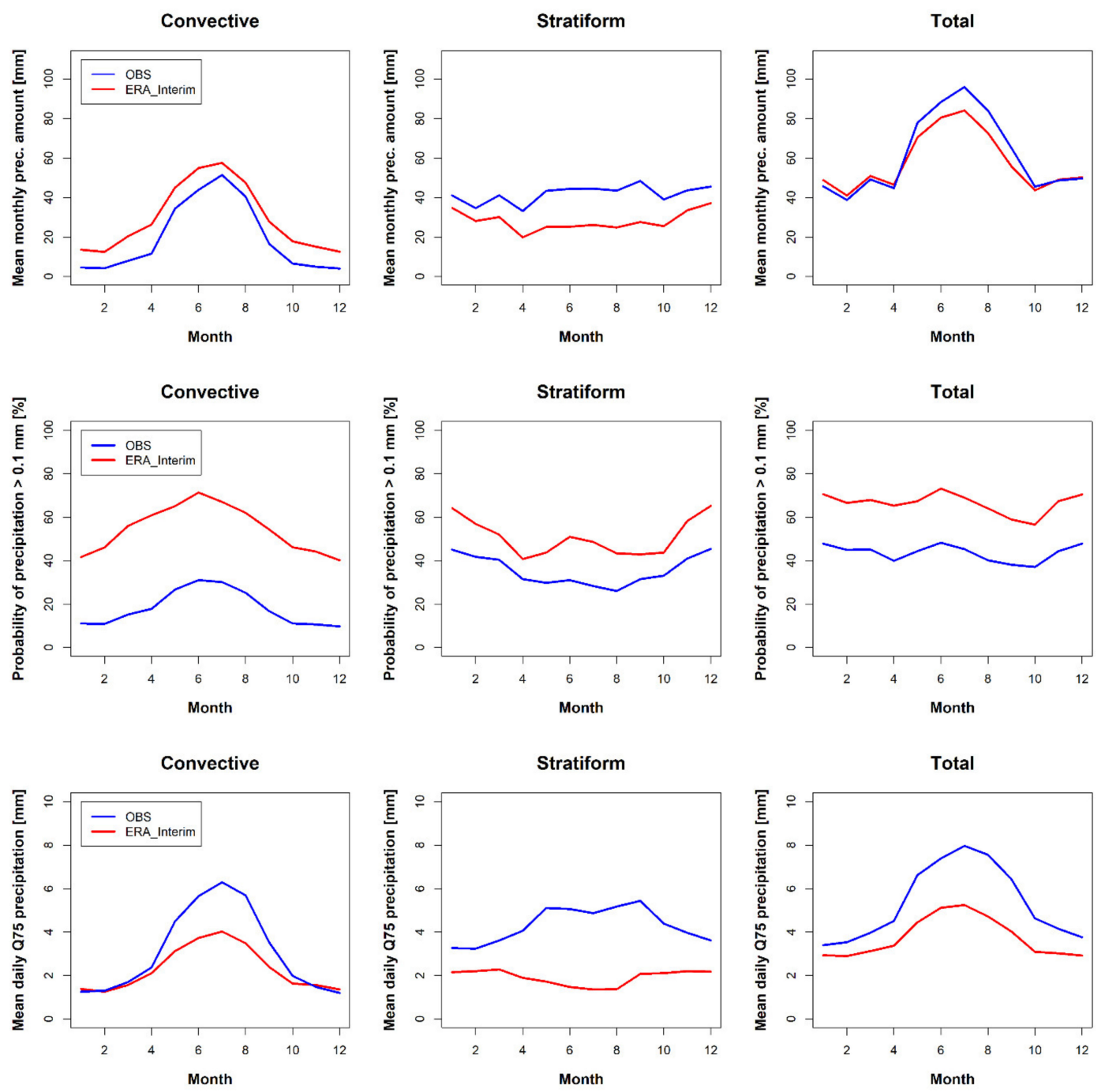

Figure 2. Mean annual cycle of monthly precipitation amounts (top), precipitation probability (middle), and 75th percentile of daily precipitation amounts (bottom) in observations (OBS) and ERA-Interim. Precipitation characteristics are averaged for stations (blue) and grid boxes (red) over the area of the Czech Republic.

The probability of the total precipitation averaged over stations (Figure 2, middle row) is approximately constant during the year (with an average of $44 \%$ ). The probability of convective precipitation has a noticeable annual cycle with the maximum in summer (almost $30 \%$ ), while the probability of stratiform precipitation is smaller in summer than in winter. The daily mean values of the thresholds for notable precipitation are shown in Figure 2 (bottom). The convective and total precipitation thresholds evidence large maxima in summer, while the annual cycle of stratiform precipitation thresholds is nearly flat.

Although in ERA-Interim, the mean monthly convective precipitation amounts are overestimated and the stratiform precipitation is mostly underestimated during the whole year in comparison to the mean station data, the mean annual cycle of the total precipitation with its maximum in summer and minimum in winter is reproduced reasonably well (Figure 2, top). On the other hand, ERA-Interim overestimates the precipitation probability for convective precipitation by more than $100 \%$. The annual cycle of thresholds for convective precipitation is in accordance with that of the station data, but the values in the warm part of the year are markedly underestimated in ERA-Interim. Obviously, summer convective precipitation in the reanalysis data appears more frequently but is less intensive than observed at the stations. Moreover, the stratiform precipitation thresholds are lower than in observations during the whole year and are lower in summer than in winter. 
The temperature thresholds (the 10th and 90th percentiles of daily Tx and Tn) have a strong annual cycle, with the minimum in winter and the maximum in summer. The mean January, April, July and October temperature thresholds calculated from the 11 stations are given in Table 2. The mean temperature thresholds are slightly higher in ERA-Interim than in the observations, but the differences are lower than $1^{\circ} \mathrm{C}$ for the majority of days.

\subsection{Frequency of Compound Events}

We calculated the number of days with a compound event for every station (grid box) and every season separately. The spatial mean, minimum, and maximum per season over all stations (grid boxes) were then calculated (Table 4). The mean percentage of compound events over the total number of extreme-temperature days per season was also computed (Table 4). For example, we detected between 2 and 36 events (the range is called the interstation range) of notable winter convective precipitation with warm days (Tx90) for the examined period. It amounts to 17 days when averaged over all stations and it corresponds to $5.4 \%$ of all warm winter days (first box in Table 4 ). Figure 3 shows the frequency of compound events expressed as a ratio by Equation (3).

Table 4. Frequency of compound events (days per season). Means and ranges (second line) for the 11 stations (OBS) or the 33 grid boxes of ERA-Interim (ERA) for the period 1982-2016. Mean percentage of days with compound events over the total extreme-temperature days per season is given in parentheses. Compound events with a mean frequency greater than 30 days for stratiform (20 days for convective) precipitation are denoted in bold.

\begin{tabular}{|c|c|c|c|c|c|c|c|c|}
\hline \multirow{2}{*}{ Convective } & \multicolumn{2}{|c|}{ Tx90 } & \multicolumn{2}{|c|}{ Tn90 } & \multicolumn{2}{|c|}{ Tx10 } & \multicolumn{2}{|c|}{ Tn10 } \\
\hline & OBS & ERA & OBS & ERA & OBS & ERA & OBS & ERA \\
\hline \multirow{2}{*}{ DJF } & $17(5.4)$ & $57(17.8)$ & $15(5.0)$ & $58(18.2)$ & $2(0.5)$ & $5(1.4)$ & $2(0.5)$ & $3(1.0)$ \\
\hline & $2-36$ & $38-74$ & $3-35$ & $42-75$ & $0-6$ & $2-7$ & $0-5$ & $0-7$ \\
\hline \multirow{2}{*}{ MAM } & $19(5.9)$ & $21(6.5)$ & $20(6.2)$ & 54 (16.5) & $10(3.1)$ & $53(16.2)$ & $12(3.6)$ & $29(8.8)$ \\
\hline & $10-23$ & $9-31$ & $6-32$ & $41-78$ & $1-24$ & $34-65$ & $4-30$ & 19-39 \\
\hline \multirow{2}{*}{ JJA } & $36(11.2)$ & $32(9.7)$ & $20(6.5)$ & $36(11.1)$ & $16(5.0)$ & $70(21.6)$ & $13(4.0)$ & $32(9.8)$ \\
\hline & $24-51$ & $16-45$ & $7-40$ & $20-57$ & $5-26$ & $60-87$ & $3-25$ & $20-52$ \\
\hline \multirow{2}{*}{ SON } & $12(3.6)$ & $36(11.1)$ & $12(3.7)$ & $60(18.8)$ & $13(4.0)$ & $52(16.3)$ & $8(2.7)$ & $17(5.1)$ \\
\hline & $4-25$ & $27-48$ & $3-27$ & $44-74$ & $2-22$ & $34-67$ & $1-21$ & $9-26$ \\
\hline \multirow{2}{*}{ Stratiform } & \multicolumn{2}{|c|}{ Tx90 } & \multicolumn{2}{|c|}{ Tn90 } & \multicolumn{2}{|c|}{ Tx10 } & \multicolumn{2}{|c|}{ Tn10 } \\
\hline & OBS & ERA & OBS & ERA & OBS & ERA & OBS & ERA \\
\hline \multirow{2}{*}{ DJF } & $41(12.9)$ & $70(22.0)$ & $47(15.1)$ & $80(25.1)$ & $21(6.8)$ & $26(8.1)$ & $16(5.1)$ & $15(4.8)$ \\
\hline & $8-73$ & $35-106$ & $23-74$ & 49-114 & $9-44$ & $15-39$ & $7-50$ & $11-27$ \\
\hline \multirow{2}{*}{ MAM } & $9(2.7)$ & $13(3.9)$ & $18(5.5)$ & $34(10.4)$ & 59 (18.2) & $73(22.2)$ & $25(7.8)$ & $28(8.7)$ \\
\hline & $5-14$ & $4-24$ & $4-30$ & $21-49$ & $37-86$ & 58-89 & $7-73$ & $18-41$ \\
\hline \multirow{2}{*}{ JJA } & $8(2.5)$ & $17(5.0)$ & $5(1.7)$ & $11(3.5)$ & $76(23.6)$ & $101(31.1)$ & $27(8.4)$ & 39 (11.8) \\
\hline & $1-13$ & $6-26$ & 0-19 & $0-25$ & $58-103$ & 80-133 & $10-65$ & $24-57$ \\
\hline \multirow{2}{*}{ SON } & $14(4.5)$ & $25(7.9)$ & $19(6.0)$ & 39 (12.1) & 49 (15.5) & $68(21.0)$ & $20(6.4)$ & $22(6.8)$ \\
\hline & $6-18$ & $17-33$ & $2-35$ & $21-56$ & $31-67$ & $52-87$ & $4-65$ & $11-39$ \\
\hline \multirow{2}{*}{ Total } & \multicolumn{2}{|c|}{ Tx90 } & \multicolumn{2}{|c|}{$\operatorname{Tn} 90$} & \multicolumn{2}{|c|}{ Tx10 } & \multicolumn{2}{|c|}{$\operatorname{Tn} 10$} \\
\hline & OBS & ERA & OBS & ERA & OBS & ERA & OBS & ERA \\
\hline \multirow{2}{*}{ DJF } & $48(15.1)$ & $81(25.5)$ & $53(17.1)$ & $90(28.0)$ & $21(6.7)$ & $22(7.0)$ & $16(5.2)$ & $13(4.1)$ \\
\hline & 9-84 & 49-115 & 26-79 & $62-120$ & $7-46$ & $14-37$ & $7-52$ & $5-26$ \\
\hline \multirow{2}{*}{ MAM } & $21(6.4)$ & $19(5.9)$ & $30(9.2)$ & 55 (16.8) & $58(17.9)$ & 81 (24.6) & $28(8.8)$ & $32(9.8)$ \\
\hline & $12-25$ & $8-30$ & $7-51$ & $42-71$ & $34-97$ & $68-100$ & $10-79$ & $20-53$ \\
\hline \multirow{2}{*}{ JJA } & 35 (10.9) & $28(8.6)$ & $21(6.7)$ & $29(8.9)$ & $71(22.0)$ & $101(31.1)$ & $29(9.3)$ & 41 (12.5) \\
\hline & $25-47$ & $12-41$ & $4-52$ & $12-51$ & $55-98$ & $87-127$ & $15-68$ & $25-59$ \\
\hline \multirow{2}{*}{ SON } & $20(6.3)$ & 35 (10.9) & $25(7.8)$ & 60 (18.7) & $52(16.2)$ & $80(24.7)$ & $24(7.5)$ & $25(7.6)$ \\
\hline & $8-29$ & $25-46$ & $3-44$ & $38-75$ & $35-73$ & $61-97$ & $7-73$ & $15-41$ \\
\hline
\end{tabular}




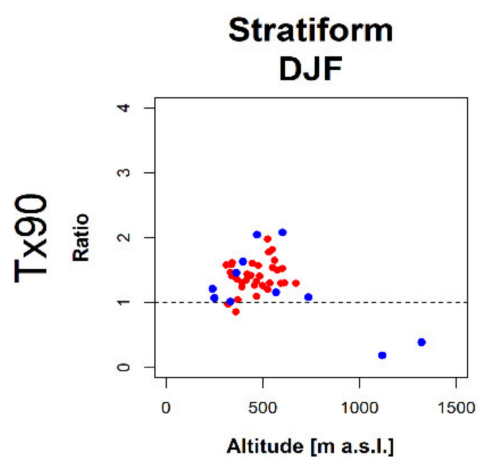

DJF

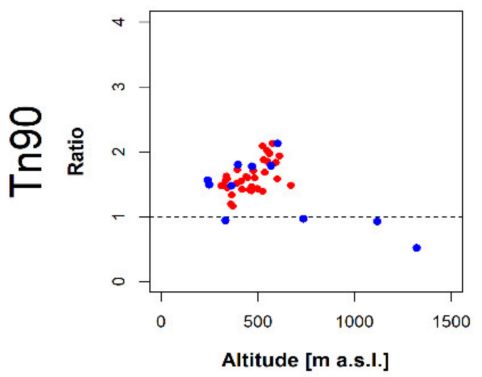

DJF

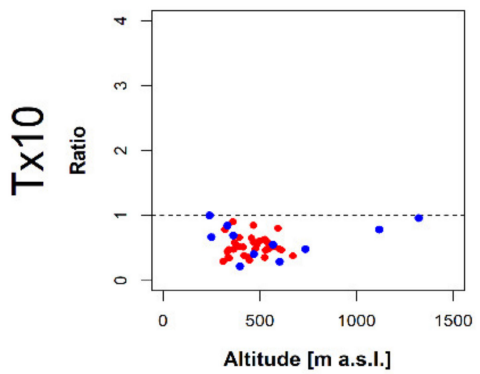

DJF

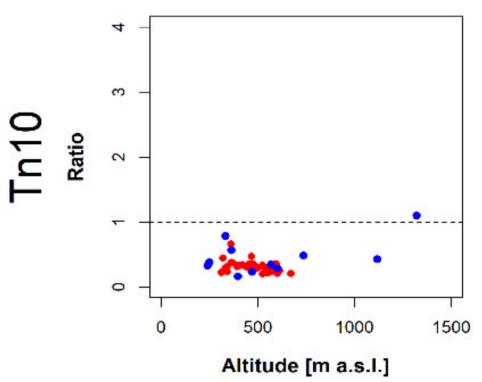

Stratiform

JJA

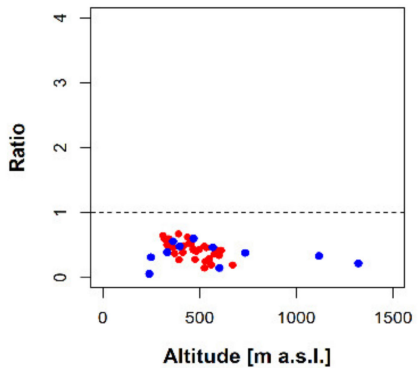

JJA

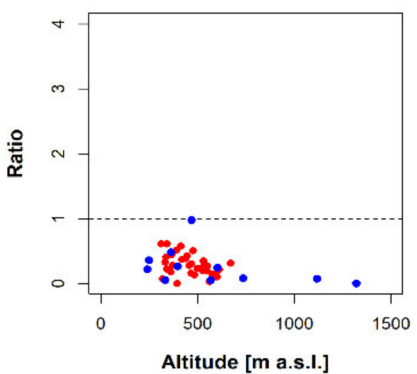

JJA

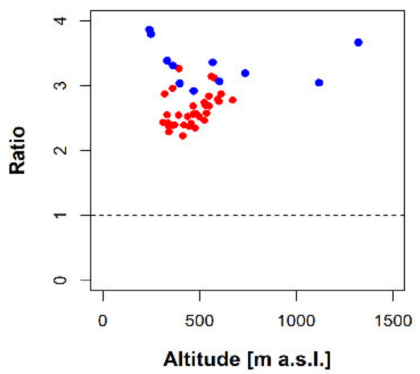

JJA

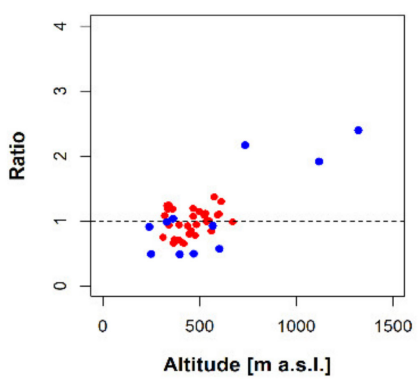

Convective

JJA

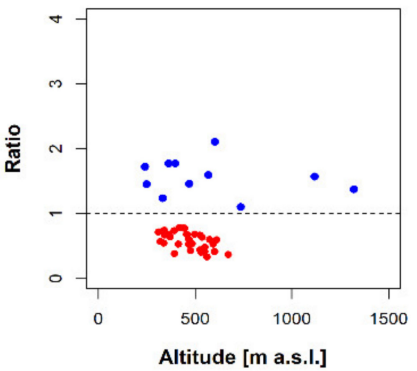

JJA

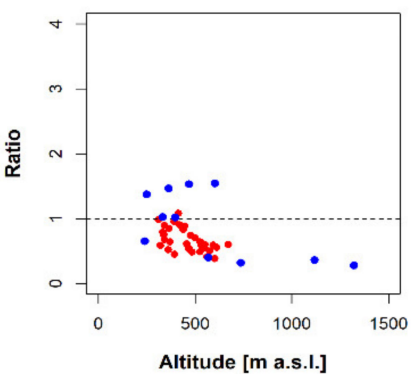

JJA

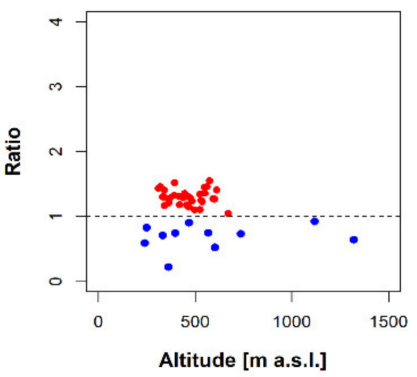

JJA

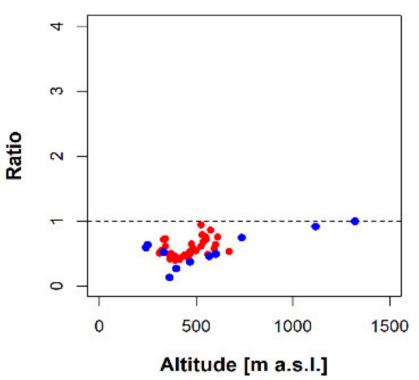

Figure 3. Dependence between the geographical altitude and the frequency of extreme temperature events occurring simultaneously with heavy precipitation events for stratiform (1st and 2nd columns) or convective (3rd column) precipitation in winter and summer, expressed as ratios to the expected value (to the unconditional frequency of the given kind notable precipitation in the given season). Blue points depict data for each station, while red points depict data for ERA-Interim grids.

For the station data, compound events of convective precipitation occur more frequently in summer than in the other seasons. Most often, they are joined with warm days (Table 4). In the 35-year-long examined period, there are 36 days when notable convective precipitation coincides with warm days. This occurs in $11 \%$ of all warm days. The number 
of days ranges from 24 to 51 at the individual stations, and for all stations, the ratio over the expected value is $>1$ (Figure 3). Notable convective precipitation is also joined with warm nights (20 days) in both spring and summer, but the ratio over the expected value is $>1$ only for half of the stations.

The notable stratiform precipitation events most frequently coincide with warm days and warm nights (41 and 47 days, respectively) in winter, but the interstation range is large (8-73 and 23-74 days, respectively). This large interstation range can be explained by the influence of altitude on stratiform precipitation [24]. The altitude dependence is visible mainly for stratiform precipitation joined with warm days in Figure 3, where the ratio over the expected value is $>1$ for all stations except for the two mountain stations. In the other seasons, events connecting notable stratiform precipitation with cold days prevail. In summer, even $24 \%$ of all cold days are connected with notable stratiform precipitation, and the ratio over the expected value is larger than 3 (i.e., three times more probable than expected) for the majority of the stations. The number of compound events with total notable precipitation reflects sums for both convective and stratiform precipitation events (Table 4).

The results from ERA-Interim do not fully correspond with those obtained from the stations. In contrast to the observations, the most frequently occurring compound events of convective precipitation are connected to cold days (70 days in summer). While the ratio compared to the expected value is $<1$ for the station data, it is $>1$ for all ERA-Interim grid boxes (Figure 3). Although there is a similar number of days with notable convective precipitation joined with warm days in ERA-Interim in comparison with the mean observed climate ( 32 vs. 36 days), the ratio over the expected value is $<1$ for all grid boxes because of the higher probability of precipitation days in ERA-Interim. ERA-Interim also overestimates the most frequent stratiform compound events, i.e., those connected with warm days and warm nights in winter (the number of events is higher by $70 \%$ ) and with cold days in the other seasons.

\subsection{Atmospheric Circulation Associated with Compound Events}

Associations with circulation types were investigated only for the station data and for those compound events which appeared at least 30 times (20 times) for stratiform (convective) precipitation during the whole examined period when the average occurrences in station data are considered (see Table 4, where these events are highlighted in bold). We determined the circulation type for every day with a given compound event from all stations. If a day with a given compound event occurred at more than one station, we took that day only one time. The total number of days with compound events is given in Table 5 (in italics). The percentage of days with the most frequent circulation types (the first three types or types with frequency higher than $10 \%$ ) with the given compound event (\%CE) and the circulation ratio $\left(R_{c}\right)$ are stated in Table 5. For abbreviations and definitions of the circulation types, see Table 3.

In summer, notable convective precipitation coinciding with warm days is associated mainly with anticyclonic type (A, this occurs in $37 \%$ of all days with this compound event), cyclonic type (C, 11\% of days), and northwest straight type (NW, $9 \%$ of days). These same types prevail also for notable convective precipitation coinciding with warm nights in spring. In summer, instead of NW type, northeast straight type (NE, 12.9\%) appears as the prevailing type. NE type occurs more frequently during this compound event than is usual in summer $=1.6$, see Table 5 ). For all three mentioned compound events, the $R_{c}$ of $C$ type is $>1.5$. 
Table 5. Most frequent circulation types for given compound events. Percentage of days with the compound event and circulation type from all days with the compound event in a season (\%CE). Table 1. 0 are highlighted). Numbers of days with given compound events from all stations are in italics.

\begin{tabular}{|c|c|c|c|c|c|c|}
\hline & $\begin{array}{c}\text { Extreme } \\
\text { Season } \\
\text { Counts }\end{array}$ & $\begin{array}{c}\text { Cirk. \%CE }\left(R_{c}\right) \\
\text { Types }\end{array}$ & $\begin{array}{c}\text { Extreme } \\
\text { Season } \\
\text { Counts }\end{array}$ & $\begin{array}{c}\text { Cirk. \%CE }\left(R_{c}\right) \\
\text { Types }\end{array}$ & $\begin{array}{l}\text { Extreme } \\
\text { Season } \\
\text { Counts }\end{array}$ & $\begin{array}{c}\text { Cirk. \%CE }\left(\mathbf{R}_{\mathrm{c}}\right) \\
\text { Types }\end{array}$ \\
\hline \multirow{3}{*}{ Convective } & Tx90 & A $37.3(\mathbf{1 . 1})$ & $\operatorname{Tn} 90$ & C $21.4(1.7)$ & Tn90 & A $29.3(0.8)$ \\
\hline & JJA & C $11.4(\mathbf{1 . 6})$ & MAM & A $17.1(0.7)$ & JJA & C 12.9 (1.8) \\
\hline & 193 days & NW 9.3 (1.2) & 140 days & NW 12.1 (1.4) & 140 days & NE 12.9 (1.6) \\
\hline \multirow{8}{*}{ Stratiform } & & NW $23.8(2.2)$ & & A $20.5(0.7)$ & & \\
\hline & Tx90 & SW 20.5 (1.3) & Tn90 & NW 20.0 (1.9) & & \\
\hline & DJF & A $17.8(0.6)$ & DJF & SW 17.3 (1.1) & & \\
\hline & 185 days & ANW 15.7 (2.1) & 220 days & ANW 16.4 (2.2) & & \\
\hline & & A $28.2(\mathbf{1 . 2})$ & & A $33.1(0.9)$ & & A $24.1(0.8)$ \\
\hline & Tx10 & C 14.3 (1.1) & Tx10 & NW 13.6 (1.7) & Tx10 & NW 14.5 (1.7) \\
\hline & MAM & & JJA & & SON & C 11.8 (1.5) \\
\hline & 280 days & NE 12.5 (1.4) & 338 days & NE 12.4 (1.6) & 228 days & NE $10.5(\mathbf{2 . 7})$ \\
\hline
\end{tabular}

In winter, notable stratiform precipitation compounding with warm days and warm nights is connected with the same circulation types: A, NW, hybrid anticyclonic northwest type (ANW), and southwest straight type (SW). The most crucial are NW and ANW types, because during these compound events, these two types occur approximately two times more frequently than is usual in winter.

In the other seasons, we analyzed notable stratiform precipitation occurring with cold days. The compound event is associated mainly with A, C, and NE circulation types in spring and with $\mathrm{A}, \mathrm{NW}$, and NE in summer. NW and NE types occur more frequently during days with the compound event than is usual in summer $\left(R_{c}=1.7\right.$ and 1.6, respectively). In autumn, the compound is linked to A, NW, C, and NE circulation types. The most crucial is the NE circulation type, because during the compound events, the NE type occurs almost three times more frequently than is usual for autumn days. It should be pointed out, however, that NE-type circulation occurs on $4 \%$ of all autumn days, hence the sampling error might be larger than for some other circulation types.

It is noteworthy that compound events often occur during days characterized by the circulation types most frequently occurring in the Czech Republic: A type (occurring on nearly $30 \%$ of all days), SW straight type (12\% of days), and C type ( $8.5 \%$ of days). The frequency of the individual circulation types differs slightly between seasons.

\section{Discussion and Conclusions}

Events of notable convective and stratiform precipitation corresponding with extreme temperature were analyzed for the period 1982-2016. We analyzed daily data from 11 stations in the Czech Republic where SYNOP reports were available and convective and stratiform precipitation data were distinguished. We compared the results with those obtained from the gridded ERA-Interim reanalysis over the area of the Czech Republic. The most frequent associations of compound events with atmospheric circulation types were subsequently investigated. The main findings of this study lead to the following conclusions:

- Notable stratiform precipitation most frequently coincides with warm nights and warm days in winter ( 47 and 41 days, respectively, over the examined period) and in the other seasons with cold days. In summer, almost a quarter of all cold days are connected with notable stratiform precipitation.

- Compound events with notable convective precipitation occur most frequently in summer and are linked mainly to warm days and warm nights (36 and 20 days, respectively).

- Cold nights coinciding with either stratiform or convective notable precipitation are rare throughout the year. 
- Although ERA-Interim overestimates the number of days with stratiform compound events, the results obtained from its data are qualitatively comparable with those from the station data.

- ERA-Interim is not able to reproduce convective compound events such as those obtained from the station data. In ERA-Interim, the most frequently occurring compound events of convective precipitation are combined with cold days.

- Notable winter stratiform precipitation coinciding with warm days and warm nights is connected with A, SW, NW, and ANW circulation types. The most crucial circulation type for notable stratiform precipitation coinciding with cold days is the NE type in all seasons except winter.

- Finally, notable convective precipitation coinciding with warm days in summer is associated with A, C, and NW types.

Although ERA-Interim is frequently used as a representation of the observed data, e.g., $[4,21]$, there are some differences: the station data represent point variables while reanalysis consists of the gridded data representing area average variables. We have shown that ERA-Interim underestimates the 75th quantile of both stratiform and convective precipitation (Figure 2, bottom) in comparison to the averaged station data, and this underestimation is larger in summer. Lovino et al. [26] revealed that extreme precipitation events are more difficult to reproduce by ERA-Interim because reanalysis smooths out the spatial distribution of intense precipitation events. Gevorgyan [29] highlighted that both the temporal and spatial variability of daily precipitation amounts are better reproduced in the cold period than in the warm period, and we obtained similar results. Another deficiency is the too smooth orography in ERA-Interim [30,31]. Although there are qualitative differences between the observations and ERA-Interim in some characteristics of precipitation and temperature due to their different distributions, we tried to limit their influences on the results by defining compound events by percentiles and not by the fixed values.

ERA-Interim strongly overestimates the compound events connecting to stratiform precipitation, mainly those which compound with warm days and warm nights in winter and with cold days in summer. The overestimation is caused by the higher frequency of rainy days in ERA-Interim than in the station data, resulting in more days with notable precipitation in ERA-Interim. ERA-Interim tends to join summer convective precipitation with cold days instead of with warm days or warm nights as that is detected in the station data. This may be the result of imperfections in convective precipitation schemes implemented in ERA-Interim. Convective precipitation in ERA-Interim originates from the parameterization of convection [32]. Bechtold et al. [33] dealt with the representation of the diurnal cycle of convective precipitation over land using Tiedtke's convective scheme and exposed too-early triggering of convective precipitation after sunrise, which may influence the relationship with temperature. As indicated by our results, the shortcomings in the convection parameterizations influence the frequency (and/or intensity) of modelled compound events. Therefore, more realistic convection or convection permitting simulation (as is shown in [30]) and reproduction of links between various meteorological variables are necessary steps to improve numerical weather prediction and regional climate modeling of extreme and compound events.

Our results on compound events are directly comparable only with a few previous studies wherein the same compound events definition was used. Tencer et al. [14] dealt with joint temperature and total precipitation extremes over Canada. They found that cold nights and heavy precipitation events tend not to occur simultaneously throughout the year. On the contrary, warm nights or warm days and heavy precipitation events are significantly positively related during autumn and winter, and cold days occur together with intense precipitation more frequently during spring and summer. This is in general agreement with our results.

Notable winter stratiform precipitation connects most frequently with warm nights and warm days. These warm nights and days may be connected with advection of warm, 
moist air associated with westerly flow (NW, SW, and ANW types, Table 5) or with the crossing of a warm front that brings precipitation to Central Europe. In summer, notable stratiform precipitation is most frequently occurring with cold days in the observed data and it is connected to cold moist advection from the north (NE and NW types). Notable summer convective precipitation is most often joined with warm days. During warm days in summer, deep convection with heavy convective precipitation may develop (A type) or intense convective precipitation appears in the atmosphere ahead of a cold front (C type).

Our results show that warm days and warm nights are linked to notable stratiform precipitation in winter and with notable convective precipitation in summer. Although there are many uncertainties in the complexity of climate change, projected warming may lead to the increase in the frequency of these compound events in the future. This would cause more of dangerous phenomena such as large-scale floods from melting snow in winter and flash floods with impacts on agriculture in the growing season.

Supplementary Materials: The following are available online at https:/ /www.mdpi.com/2073-443 3/12/1/87/s1, Figure S1: Grid points used to construct the circulation indices for central Europe.

Author Contributions: Z.R. suggested the methodology, prepared and analyzed the data, contributed to the interpretation of the results, and wrote a draft of the manuscript. R.B. contributed to data analyzing and interpretation of the results and compiled and edited the manuscript. E.P. prepared circulation indices, contributed to the interpretation of the results, and compiled and edited the manuscript. All authors have read and agreed to the published version of the manuscript.

Funding: Z.R. was supported by the Programme to support prospective human resources-post Ph.D. candidates in the Czech Academy of Sciences. E.P. was supported by The Ministry of Education, Youth and Sports of the Czech Republic, program INTER-COST no. LTC19044. R.B. was supported by the Czech Science Foundation, project no. 20-28560S.

Institutional Review Board Statement: Not applicable.

Informed Consent Statement: Not applicable.

Data Availability Statement: The ERA-Interim reanalysis dataset is available from the European Centre for Medium Range Weather forecasts http:/ / www.ecmwf.int/en/research/climate-reanalysis / era-interim.

Acknowledgments: The ERA-Interim reanalysis dataset is available from the European Centre for Medium Range Weather forecasts http:/ / www.ecmwf.int/en/research/climate-reanalysis/erainterim. Z.R. was supported by the Programme to support prospective human resources-post Ph.D. candidates in the Czech Academy of Sciences. E.P. was supported by The Ministry of Education, Youth and Sports of the Czech Republic, program INTER-COST no. LTC19044. R.B. was supported by the Czech Science Foundation, project no. 20-28560S. We thank anonymous reviewers whose comments contributed significantly to the improvement of the paper.

Conflicts of Interest: The authors declare no conflict of interest.

\section{References}

1. Bevacqua, E.; Maraun, D.; Hobæk Haff, I.; Widmann, M.; Vrac, M. Multivariate statistical modelling of compound events via pair-copula constructions: Analysis of floods in Ravenna (Italy). Hydrol. Earth Syst. Sci. 2017, 21, 2701-2723. [CrossRef]

2. Plavcová, E.; Urban, A. Intensified Impacts on Mortality Due to Compound Winter Extremes in the Czech Republic. Sci. Total Environ. 2020, 746, 141033. [CrossRef] [PubMed]

3. Sedlmeier, K.; Feldmann, H.; Schädler, G. Compound summer temperature and precipitation extremes over central Europe. Theor. Appl. Climatol. 2018, 131, 1493-1501. [CrossRef]

4. Martius, O.; Pfahl, S.; Chevalier, C. A global quantification of compound precipitation and wind extremes. Geophys. Res. Lett. 2016, 43, 7709-7717. [CrossRef]

5. Hao, Z.; Singh, V.P.; Hao, F. Compound Extremes in Hydroclimatology: A Review. Water 2018, 10, 718. [CrossRef]

6. Zscheischler, J.; Westra, S.; van den Hurk, B.J.J.M.; Seneviratne, S.I.; Ward, P.J.; Pitman, A.; AghaKouchak, A.; Bresch, D.N.; Leonard, M.; Wahl, T.; et al. Future climate risk from compound events. Nat. Clim. Chang. 2018, 8, 469-477. [CrossRef]

7. Tencer, B.; Bettolli, M.L.; Rusticucci, M. Compound temperature and precipitation extreme events in southern South America: Associated atmospheric circulation, and simulations by a multi-RCM ensemble. Clim. Res. 2016, 68, $183-199$. 
8. Assani, A.A.; Guerfi, N. Analysis of the Joint Link between Extreme Temperatures, Precipitation and Climate Indices in Winter in the Three Hydroclimate Regions of Southern Quebec. Atmosphere 2017, 8, 75.

9. Eisenberg, D.; Warner, K.E. Effects of snowfalls on motor vehicle collisions, injuries, and fatalities. Am. J. Public Health 2005, 95, 120-124. [CrossRef]

10. Akstinas, V.; Meilutyte-Lukauskiene, D.; Kriauciuniene, J.; Šarauskiene, D. Features and causes of catastrophic floods in the Nemunas River basin. Hydrol. Res. 2020, 51, 308-321. [CrossRef]

11. Te Beest, D.E.; Paveley, N.D.; Shaw, M.W.; van den Bosch, F. Disease-weather relationships for powdery mildew and yellow rust on winter wheat. Phytopathology 2008, 98, 609-617. [CrossRef] [PubMed]

12. Beniston, M. Trends in joint quantiles of temperature and precipitation in Europe since 1901 and projected for 2100. Geophys. Res. Lett. 2009, 36, L07707. [CrossRef]

13. Arsenović, P.; Tošić, I.; Unkašević, M. Trends in combined climate indices in Serbia from 1961 to 2010. Meteorol. Atmos. Phys. 2015, 127, 489-498. [CrossRef]

14. Tencer, B.; Weaver, A.; Zwiers, F. Joint Occurrence of daily temperature and precipitation extreme events over Canada. J. Appl. Meteorol. Clim. 2014, 53, 2148-2162. [CrossRef]

15. Berg, P.; Moseley, C.; Haerter, J.O. Strong increase in convective precipitation in response to higher temperatures. Nat. Geosci. 2013, 6, 181-185. [CrossRef]

16. Fischer, A.M.; Keller, D.E.; Liniger, M.A.; Rajczak, J.; Schär, C.; Appenzeller, C. Projected changes in precipitation intensity and frequency in Switzerland: A multi-model perspective. Int. J. Climatol. 2015, 35, 3204-3219. [CrossRef]

17. Rulfová, Z.; Beranová, R.; Kyselý, J. Climate change scenarios of convective and large-scale precipitation in the Czech Republic based on EURO-CORDEX data. Int. J. Climatol. 2017, 37, 2451-2465. [CrossRef]

18. Harpa, G.-V.; Croitoru, A.-E.; Djurdjevic, V.; Horvath, C. Future changes in five extreme precipitation indices in the lowlands of Romania. Int. J. Climatol. 2019, 39, 5720-5740. [CrossRef]

19. Andrade, C.; Leite, S.M.; Santos, J.A. Temperature extremes in Europe: Overview of their driving atmospheric patterns. Nat. Hazards Earth Syst. Sci. 2012, 12, 1671-1691. [CrossRef]

20. Horton, D.E.; Johnson, N.C.; Singh, D.; Swain, D.L.; Rajaratnam, B.; Diffenbaugh, N.S. Contribution of changes in atmospheric circulation patterns to extreme temperature trends. Nature 2015, 522, 465-469. [CrossRef]

21. Li, M.; Yao, Y.; Luo, D.; Zhong, L. The Linkage of the Large-Scale Circulation Pattern to a Long-Lived Heatwave over Mideastern China in 2018. Atmosphere 2019, 10, 89. [CrossRef]

22. Blenkinsop, S.; Chan, S.C.; Kendon, E.J.; Roberts, N.M.; Fowler, H.J. Temperature influences on intense UK hourly precipitation and dependency on large-scale circulation. Environ. Res. Lett. 2015, 10, 054021. [CrossRef]

23. Cioffi, F.; Lall, U.; Rus, E.; Krishnamurthy, C.K.B. Space-time structure of extreme precipitation in Europe over the last century. Int. J. Climatol. 2015, 35, 1749-1760. [CrossRef]

24. Rulfová, Z.; Kyselý, J. Disaggregating convective and stratiform precipitation from station weather data. Atmos. Res. 2013, 134, 100-115. [CrossRef]

25. Dee, D.P.; Uppala, S.M.; Simmons, A.J.; Berrisford, P.; Poli, P.; Kobayashi, S.; Andrae, U.; Balmaseda, M.A.; Balsamo, G.; Bauer, D.P.; et al. The ERA-Interim reanalysis: Configuration and performance of the data assimilation system. Q. J. Roy. Meteorol. Soc. 2011, 137, 553-597.

26. Lovino, M.A.; Müller, O.V.; Berbery, E.H.; Müller, G.V. How have daily climate extremes changed in the recent past over northeastern Argentina? Glob. Planet. Chang. 2018, 168, 78-97. [CrossRef]

27. Jenkinson, A.F.; Collison, F.P. An initial climatology of gales over the North Sea. Synop. Climatol. Branch. Memorandum. 1977, 1-62.

28. Plavcová, E.; Kyselý, J. Evaluation of daily temperatures in Central Europe and their links to large-scale circulation in an ensemble of regional climate models. Tellus 2011, 63, 763-781. [CrossRef]

29. Gevorgyan, A. Verification of daily precipitation amount forecasts in Armenia by ERA-Interim model. Int. J. Climatol. 2013, 33, 2706-2712. [CrossRef]

30. Warrach-Sagi, K.; Schwitalla, T.; Wulfmeyer, V.; Bauer, H.-S. Evaluation of a climate simulation in Europe based on the WRFNOAH model system: Precipitation in Germany. Clim. Dynam. 2013, 41, 755-774. [CrossRef]

31. Odon, P.; West, G.; Stull, R. Evaluation of Reanalyses over British Columbia. Part I: Daily and Extreme 2-m Temperature. J. Appl. Meteorol. Clim. 2018, 57, 2091-2111. [CrossRef]

32. Tiedtke, M. A comprehensive mass flux scheme for cumulus parametrization in large-scale models. Mon. Weather Rev. 1989, 117, 1779-1800. [CrossRef]

33. Bechtold, P.; Chaboureau, J.-P.; Beliaars, A.; Betts, A.K.; Köhler, M.; Miller, M.; Redelsperger, J.-L. The simulation of the diurnal cycle of convective precipitation over land in a global model. Q. J. Roy. Meteor. Soc. 2004, 130, 3119-3137. [CrossRef] 